\title{
USE OF TOPICAL DICLOFENAC IN ASSOCIATION WITH EXTERNAL OCULAR COMPRESSION
}

\author{
P. H. CONSTABLE and G. G. W. ADAMS \\ Romford
}

\begin{abstract}
SUMMARY
This study investigated the effect of pretreatment with topical diclofenac $0.1 \%$ on the changes in intraocular pressure (IOP) associated with use of an external ocular compression device. The IOP reduction in eyes receiving pretreatment was significantly greater than in controls after 40 minutes of compression, and the recovery in IOP after removal of the compression device was significantly reduced. We conclude that the IOP rise after such compression is largely prostaglandin mediated, and suggest that use of ocular compression devices is associated with marked intraocular prostaglandin release.
\end{abstract}

The use of external ocular compression devices to reduce the intraocular pressure (IOP) prior to cataract surgery is well established. Following removal of the device, there is a rapid rebound recovery in IOP to baseline levels, and animal models have identified that prostaglandins are mediators for this IOP increase. This study aimed to investigate the effect of pretreatment with topical diclofenac sodium $0.1 \%$ (Voltarol Ophtha, CIBA Vision Ophthalmics, UK) in human volunteers receiving external ocular compression, to establish whether the IOP change was significantly altered by the use of this topical non-steroidal anti-inflammatory drug.

\section{METHOD}

Thirty volunteers from the ophthalmology department, staff and patients, were used in this ethically approved study. Subjects were randomised to receive either ocular compression alone, or ocular compression following pretreatment with topical diclofenac $0.1 \%$. The eye to be tested was selected at random. Subjects with a history of previous ophthalmic surgery, glaucoma, uveitis, systemic vascular disease, or who were receiving any systemic antiinflammatory drug, were excluded from the study. Subjects in the study group received pretreatment to the test eye of one drop of topical diclofenac $0.1 \%$ every 15 min-

Correspondence to: Mr P. H. Constable, Registrar in Ophthalmology, Oldchurch Hospital, Romford, Essex RM7 0BE. UK. utes in the hour prior to applying the external compression device. All subjects lay supine with one pillow behind the head throughout the test period, and received external ocular compression to one eye using a MacIntyre mercury weight (Microsurgical Technology, USA) following a standardised protocol. Compression was applied for 40 minutes, and the recovery in IOP was monitored for a further 30 minutes. IOP measurements were made using a Keeler Airpulse tonometer (Keeler, UK), which has previously been found to give accurate reproducible IOP measurements. ${ }^{1}$ Statistical analysis of the results was performed using Student's $t$-test.

\section{RESULTS}

Results are shown in Table I. The mean age of the subjects in the study was 41.7 years, with a mean starting IOP of $18.35 \mathrm{mmHg}$. Seventeen right eyes and 13 left eyes were tested in the study. The mean age is below that of many patients undergoing cataract surgery, but the age range of our subjects was from 19 to 82 years, and we detected no obvious difference in the response across the entire age range studied. All subjects underwent a rapid and significant fall in IOP following external compression using the MacIntyre mercury weight. The test eyes demonstrated a

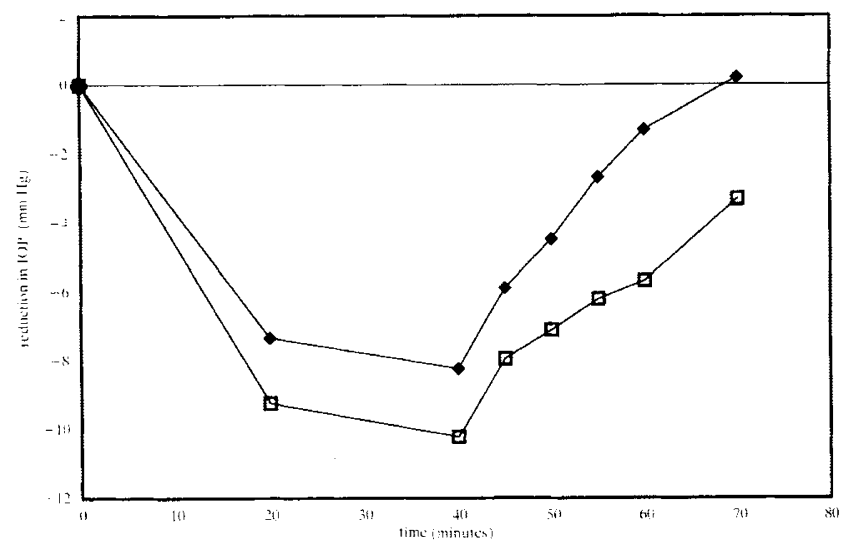

Fig. 1. Changes in intraocular pressure (IOP), either alone (filled squares) or preceded by topical diclofenac $0.1 \%$ (open squares). Compression was removed at $t=40$ minutes. 
Table I. Mean reduction in IOP with external ocular compression: test eye versus control

\begin{tabular}{|c|c|c|c|}
\hline Time $(\min )$ & Control IOP (mmHg) & Test IOP (mmHg) & $p$ value $^{\mathrm{a}}$ \\
\hline-0 & 0 & 0 & \\
\hline 20 & $-7.33(2.94)$ & $-9.23(2.54)$ & 0.069 \\
\hline 40 & $-8.23(2.18)$ & $-10.23(2.78)$ & 0.037 \\
\hline 45 & $-5.87(2.01)$ & $-7.93(3.28)$ & 0.047 \\
\hline 50 & $-4.47(2.47)$ & $-7.1 \quad(2.64)$ & 0.009 \\
\hline 55 & $-2.27(2.18)$ & $-6.2(3.04)$ & 0.001 \\
\hline 60 & $-1.3 \quad(1.74)$ & $-5.67(2.77)$ & $<0.001$ \\
\hline 70 & $0.2 \quad(1.03)$ & $-3.3 \quad(2.5)$ & $<0.001$ \\
\hline
\end{tabular}

IOP readings are change from baseline IOP measurements (SD in parentheses), made with the patient supine prior to application of the compression device. Compression was applied at $t=0$; the device was removed at $t=40$ minutes. The control group received compression alone, the test group received pretreatment with topical diclofenac $0.1 \%$ prior to compression.

astudent's $t$-test was applied, test eye versus control eye.

slightly greater reduction in IOP compared with the control group after 20 minutes of compression, with a mean reduction of $9.23 \mathrm{mmHg}$ compared with $7.33 \mathrm{mmHg}$ in the controls (SD 2.54, $p=0.069$ ). After 40 minutes of compression the control eyes had achieved a mean reduction of $8.23 \mathrm{mmHg}$ from starting IOP (SD 2.18, $p=0.001$ ), but the test group demonstrated a significantly greater reduction in IOP as compared with the controls, achieving a mean reduction of $10.23 \mathrm{mmHg}$ (SD 2.78, $p=0.037$ ).

Following removal of the compression device, both groups initially demonstrated a brisk rise in IOP over the first 5 minutes, with an increase in IOP of $2.30 \mathrm{mmHg}$ in the test eyes and $2.36 \mathrm{mmHg}$ in the control eyes - a rate of recovery of approximately $0.46 \mathrm{mmHg} / \mathrm{min}$ in each group. After this rapid initial rise, the IOP in the control group continued to recover at a brisk rate, with no significant difference from the starting IOP detected 20 minutes after removal of the compression device - an average rate of $0.35 \mathrm{mmHg} / \mathrm{min}$ over this period. The test eyes showed a marked reduction in the rate of recovery of IOP after the first 5 minutes (Fig. 1), with the rate of increase in IOP falling to $0.19 \mathrm{mmHg} / \mathrm{min}$, and an average rate of recovery of only $0.23 \mathrm{mmHg} / \mathrm{min}$ over a comparable 20 minute period. The mean reduction in IOP from starting levels 10 minutes after removal of the compression device was $6.20 \mathrm{mmHg}$ in the test eyes compared with $4.47 \mathrm{mmHg}$ in the control eyes $(p=0.009)$, and $5.67 \mathrm{mmHg}$ compared with $1.30 \mathrm{mmHg}$ in the controls at 20 minutes $(p<0.001)$. At the end of the study period the control group IOP was mildly elevated from baseline levels with an IOP increase of $0.20 \mathrm{mmHg}$, but the test eyes still maintained a significant reduction in IOP of $3.30 \mathrm{mmHg}(p<0.001)$.

\section{DISCUSSION}

External ocular compression devices are extensively used to reduce the IOP prior to cataract surgery, particularly in association with peribulbar and retrobulbar anaesthesia. The reduction in IOP of $8.23 \mathrm{mmHg}$ found in our control group after 40 minutes of compression with the MacIntyre weight compares well with other reports on the use of similar devices, and with levels achieved with general anaesthesia. ${ }^{2.3}$ The reduction in IOP in the study group, which had received pretreatment with topical diclofenac, was significantly greater than that in the control eyes after 40 minutes of compression, with a mean reduction of $10.23 \mathrm{mmHg}(p=0.037)$.

Immediately after removing the compression device, all the eyes in the study showed a similar sharp rise in IOP over the first 5 minutes, probably caused by a rebound increase in ocular blood flow as has been previously described following ocular compression. ${ }^{4}$ After this rapid initial rise in both groups, the IOP recovery remained brisk in the control eyes, with no significant difference from starting IOP detected after 20 minutes. The mean rate of recovery of IOP in the control group was $0.35 \mathrm{mmHg} / \mathrm{min}$ over this period, a level comparable with results from earlier studies of IOP recovery after ocular compression. ${ }^{5,6}$ The mechanism for this acute rise in IOP is not clear, but a similar rise is seen in animal eyes following both external ocular compression and ocular injury, and prostaglandins have been implicated as mediators of this response.

Aqueous sampling in animal eyes has demonstrated a significant increase in intraocular prostaglandin levels after ocular compression, and these have been identified as prostaglandins $\mathrm{E}_{2}$ and $\mathrm{F}_{2 \alpha}{ }^{8}$ Experiments administering direct intracameral injections of these agents have replicated this IOP rise in test eyes, confirming that prostaglandins are mediators of this response in animals. Intraocular micropipette sampling in rabbits has shown the site of action of the prostaglandins to be chiefly on the tight junction of the non-pigmented epithelium of the ciliary body, where they induce a focal breakdown of the blood-aqueous barrier. ${ }^{10}$ Mathematical modelling suggests that the change in osmotic forces caused by the resulting increase in aqueous protein levels, together with ciliary vessel vasodilatation induced by the prostaglandins, will cause the acute rise in IOP that is seen clinically."

The prostaglandins involved in this response are produced by the action of local intraocular prostaglandinsynthesising enzyme systems, which are distributed widely throughout the iris stroma. ${ }^{12}$ Inhibition of these enzymes would be predicted to block the IOP response, and animal experiments have confirmed this hypothesis, with reports of cases receiving pretreatment with intraperitoneal indomethacin or systemic aspirin showing a significant reduction in the IOP rise after ocular compression. $^{13,14}$

The test group in our study received pretreatment with topical diclofenac $0.1 \%$, a potent inhibitor of prostaglandin synthesis that acts largely through inhibition of the cyclo-oxygenase pathway. ${ }^{15}$ The IOP reduction in the test group was found to be significantly greater after 40 minutes of compression with the MacIntyre mercury bag, but more significantly the test group clearly demonstrated a marked delay in the rate of IOP recovery after the compression device was removed. After the brisk initial rise in IOP seen in both groups immediately following removal 
of the compression device, the rate of IOP recovery in the test group dropped to $0.19 \mathrm{mmHg} / \mathrm{min}$, with an average rate of recovery of $0.23 \mathrm{mmHg} / \mathrm{min}$ over the total recovery period studied. At 30 minutes after removal of the MacIntyre weight, the mean IOP reduction in the test group remained $3.3 \mathrm{mmHg}$ below baseline, compared with a mild elevation of $0.2 \mathrm{mmHg}$ above baseline in the control group $(p<0.001)$. These results suggest that the IOP rise seen after external ocular compression in humans is partly prostaglandin mediated, and that the use of topical diclofenac $0.1 \%$ is effective in blunting this response.

The recovery of IOP was not totally abolished in our test group, and this finding again concurs with the results from animal studies suggesting that other, as yet undetermined, mediators are also involved in this response. It is clear, however, that pretreatment with topical diclofenac $0.1 \%$ has a beneficial effect when used in conjunction with external ocular compression both in achieving, and in maintaining, an optimal IOP reduction prior to surgery. Prostaglandins are also recognised as potent mediators of other intraocular responses such as reactive aqueous changes, leukotaxis and pupillary miosis, ${ }^{16}$ and the implication that use of an external ocular compression device results in a significant increase in intraocular prostaglandin levels makes a further case for specifically blocking this response with topical non-steroidal antiinflammatory agents prior to surgery.

The authors would like to thank Keeler Ltd for the loan of their Pulsair 2000 Tonometer for the purposes of this study.

Key words: Diclofenac, Intraocular pressure, Ocular compression, Prostaglandin.

\section{REFERENCES}

1. Moseley M, Thompson JR, et al. Comparison of the Keeler Pulsair 200 non-contact tonometer with Goldmann applanation. Eye 1993:7:127-30.

2. Ropo A, Ruusuvaara $\mathrm{P}$, et al. Effect of ocular compression on intraocular pressure in periocular anaesthesia. Acta Ophthalmol (Copenh) 1990;68:227-9.

3. Feneck RO, Durkin MA. A comparison between the effects of fentanyl, droperidol with fentanyl and halothane anaesthesia on intraocular pressure in adults. Anaesthesia 1987;42:266-9.

4. Jay WM, Aziz MZ, Green K. Effect of digital massage on intraocular pressure and ocular and optic nerve blood flow. Acta Ophthalmol (Copenh) 1986;64:58-62.

5. Bolling JP, Kurrie RW, O'Day DM. Effect of ocular compression on intraocular pressure. Ophthalmic Surg 1985; 16:563-65.

6. Constable PH, Porter EJB. Extraocular compression prior to cataract surgery: time course of reduction and subsequent recovery of intraocular pressure. Eye 1993;7:731-4.

7. Ambache N, Kavanagh L, Whiting J. Effect of mechanical stimulation on rabbits' eyes: release of active substances in anterior chamber perfusates. J Physiol (Lond) 1965;176: 378-408.

8. Ambache N, Brummer HC. A simple chemical procedure for distinguishing $\mathrm{E}$ from $\mathrm{F}$ prostaglandins, with application to tissue extracts. Br J Pharmacol 1969;33:162-70.

9. Starr MS. Further studies on the effect of prostaglandin on intraocular pressure in the rabbit. Exp Eye Res 1971;11:170-7.

10. Nuefeld AH, Sears ML. The site of action of prostaglandin $\mathrm{E}_{2}$ on the disruption of the blood-aqueous barrier in the rabbit eye. Exp Eye Res 1973;17:445-8.

11. Green K. Permeability properties of the ciliary epithelium in response to prostaglandins. Invest Ophthalmol 1973;12: 752-8.

12. Bhattacherjee $P$, Eakins KE. Inhibition of the prostaglandin synthetase systems in ocular tissues by indomethacin. Br J Pharmacol 1974;50:227-30.

13. Miller JD, Eakins KE, Atwal M. The release of $\mathrm{PGE}_{2}$ like activity into aqueous humour after paracentesis and its prevention by aspirin. Invest Ophthalmol 1973;12:939-42.

14. Obstbaum SA, Podos MD. Ocular compression and noncorticosteroidal anti-inflammatory agents. Am J Ophthalmol 1975;79:1008-11.

15. Goa KL, Chrisp P. Ocular diclofenac. Drugs Ageing 1992;2:473-86.

16. Rowland JM, Ford JF, et al. Effect of topical diclofenac sodium in a rabbit model of ocular inflammation and leukotaxis. J Ocular Pharmacol 1986;2:23-9. 